\title{
Experimental investigation of Low velocity impact response of reinforced concrete beams without stirrups
}

\author{
Yingqian $\mathrm{Fu}^{1,2^{*}}$, Xinlu $\mathrm{Yu}^{1,2}$, Xinlong Dong ${ }^{1}$, Fenghua Zhou ${ }^{1}$ \\ ${ }^{1}$ Faculty of Mechanical Engineering and Mechanics, Ningbo University, 315211 Ningbo, China \\ ${ }^{2}$ School of Mechatronical Engineering, Beijing Institute of Technology, 100081 Beijing, China
}

\begin{abstract}
This paper presents an experimental program of reinforced concrete beam without stirrups tested by impact three-point-bending under different initial velocity (drop height). As the results shown, for the static events, the failure mode is bending firstly, and then translates to shearing. the longitudinal reinforcements play an important role for the increasing of loading during bending stage. For the impact events, reinforced concrete beams failed in a flexural failure model at slow rates of loading and in shear failure model at high impact loading rate relatively. Moreover, the shear failure and bending failure have developed during the peak stage of Force-deflection curves. That is different with the emergence sequence of cracks under static tests. So the mechanical parameters of peak stage should be considered for the resistance of concrete beam under impact loading.
\end{abstract}

\section{Introduction}

The analysis and design of reinforced concrete beams for the resistance of impact loading have been investigated by many researchers [1-3]. Numerous experimental and analytical studied have been conducted for the impactresistance of building including the failure patterns, loading, deflection, monument and energy [4-6]. Experimental studies have revealed that shear failure play an important role on the resistance of impact loading. Three-point-bending test under drop height impacting was employed widely to investigate the impact behavior of reinforced concrete beam or plate. For the most of failure patterns, in the impact threepoint-bending test, severer dialogue cracks often were found under high speed loading. However, most of experiences only focus on the relationship between loading conditions and phenomenal results, such as between impact velocity (or impact monument or impact energy ) and failure patterns, or between reinforcement ratio (or strength of matrix) and failure patterns, little effort was spent to understand the inner failure mechanism of shearing or bending of reinforced concrete beam under impact loading. Even if the numerical methods were adopted numerically to discuss the failure mechanism, but it is difficult to simulate very well for the complexity of reinforced concrete material and structure.

In this paper, a well design experimental instruments of drop height testing system was employed including the easy-controlling impactor, the accurate loading detectors, the high speed image capture system and the displacement and strain field calculation method. Especially, the Digital Image Calculation method was used to achieve the displacement and strain field on the surface of beam. This paper presents an experimental program of reinforced concrete beam without stirrups tested by impact three-point-bending under different initial velocity (drop height) and comparing with the static three-point-bending results. The failure process was investigated, and the strain state of shear failure was discussed. This paper can be helpful to understanding the effect of shear failure mechanism and supplying the further study by numerical and analytical method.

\section{Experimental program}

\subsection{Material and specimens}

The experimental program consisting of 15 beams were $70 \mathrm{~mm}$ in width, $100 \mathrm{~mm}$ in height, and $600 \mathrm{~mm}$ in length and the reinforced concrete beams without stirrups were just singly or doubly reinforced with the longitudinal reinforcement bars placed symmetrically along the bottom of the specimens with the cover of $16 \mathrm{~mm}$ in thickness as Fig. 1 shown. All specimens were cast at the same time and using the same concrete batch and curing condition to make sure the identical mechanical behavior of matrix. Ordinary Portland cement was used in this investigation with a 28 days compressive strength of $42.5 \mathrm{MPa}$ conforming to P. I. 42.5. The coarse aggregates are rounded in shape and range in size from $12 \mathrm{~mm}$ down to $5 \mathrm{~mm}$. The river sand with a specific gravity of $2600 \mathrm{~kg} / \mathrm{m}^{3}$ constituted the fine aggregate. In all mixtures, the ratio of water and cement was 0.2 . The preparation and the cure of all the mixes were conducted under laboratory conditions. Then, all

*Corresponding author: imech2012@gmail.com 
specimens were cured in a fog room for 28 days within $20 \pm 2{ }^{\circ} \mathrm{C}, 95 \%$ relative humidity.

For the impact tests, involved 12 beams, were divided into four groups in terms of impact height $\mathrm{H}_{0}$ $(1.2 \mathrm{~m}, 2.4 \mathrm{~m}, 3.6 \mathrm{~m}$ and $4.8 \mathrm{~m})$. Table 1 presents the overview of the entire test program, each group includes four tests with different drop heights, and each even includes the corresponding reinforcement ratio, mass, initial impact velocity, monument and energy. The specimen denoted by PR0.8-1.2 means 'Plain Reinforcement' beam with longitudinal reinforcement ratio 0.8 impacted at the drop height of $1.2 \mathrm{~m}$. In addition, three beams were cast to determine the static behavior of the specimens corresponding to the impact tests in the name of S-PR0.4 where 'S' means 'Static'.

Table 1. Impact test program.

\begin{tabular}{|c|c|c|c|c|}
\hline$\#$ & $\mathrm{H}_{0}(\mathrm{~m})$ & $\mathrm{V}_{0}(\mathrm{~m} / \mathrm{s})$ & $\mathrm{M}_{0}(\mathrm{~kg} . \mathrm{m} / \mathrm{s})$ & $\mathrm{E}_{0}(\mathrm{~J})$ \\
\hline PR0.8-1.2 & 1.2 & 4.85 & 186.2 & 451.6 \\
\hline PR0.8-2.4 & 2.4 & 6.86 & 263.4 & 903.2 \\
\hline PR0.8-3.6 & 3.6 & 8.40 & 322.6 & 1355 \\
\hline PR0.8-4.8 & 4.8 & 9.70 & 372.5 & 1806 \\
\hline
\end{tabular}

\subsection{Test setup and procedure}

For the impact loading, a drop-weight impact system was well design as Fig.1 shown, in which a drop hammer with a mass of $38.4 \mathrm{~kg}$ was dropped freely from three different heights $(1.2 \mathrm{~m}, 2.4 \mathrm{~m}, 3.6 \mathrm{~m}$ and $4.8 \mathrm{~m})$. The striking head of impactor had a hemispherical tip with a radius of $60 \mathrm{~mm}$, and the supporters were also designed as a hemispherical tip with a radius of $30 \mathrm{~mm}$ for allowing the beam to rotate freely. The specimens were tested under simply supported conditions with a shear span of $250 \mathrm{~mm}$, leaving $50 \mathrm{~mm}$ overhang at each end.

The impact force data acquisition system included two piezoelectric force transducers, one of was mounted to the impact mass with the maximum range of $600 \mathrm{kN}$ sandwiched between the hemispherical tip of impactor head and the upper bar as Fig. 2 shown. Then, the other load cell was placed beneath the left support hemispherical tip with the maximum range of $50 \mathrm{kN}$. Both of them were recorded on the same data logger with sampling of $1 \mathrm{MHz}$ by a high speed responding oscilloscope. At the same time, the impact events were recorded by using a high speed camera at the sampling rate of $40 \mathrm{kHz}$. An electric-photo switch which could generate a electrical single when the laser line blocked by drop-weight was employed to trigger the oscilloscope and camera synchronous.

And the images captured from high speed camera were analyzed by 2D digital image correlation method (2D-DIC) software MatchID-2D to track the motion of drop-weight and beam. The DIC technique can obtain a continuous field of displacement, strain components on the surface of specimen by comparing of the gray level distribution between deformed images and reference images. A Region of Interesting (ROI) is chose firstly as Fig. 2 shown. In this region, a lot of small sparkles are sprayed to achieve a random distribution of gray level. A rectangle region was marked on the surface of beam, at the same time, the hemispherical tip of impactor was also sprayed to achieve its movement.

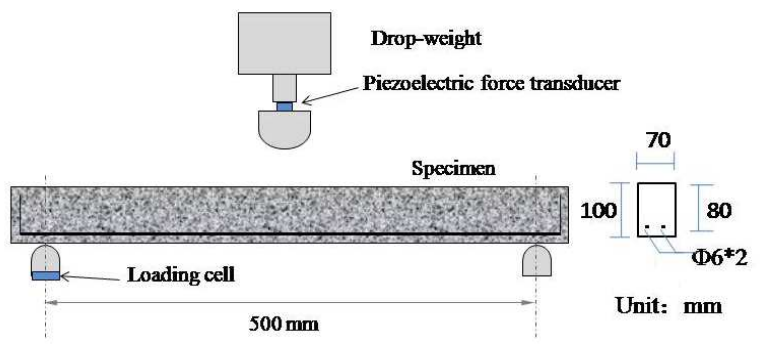

Fig. 1. Sketch of setups and specimens.

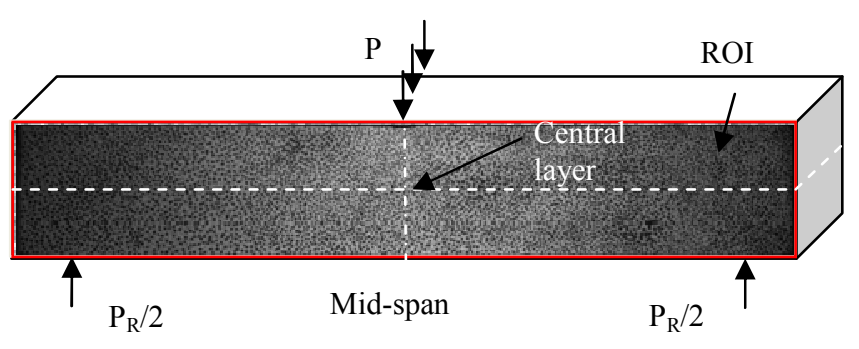

Fig. 2. ROI of DIC.

\section{Experimental results}

\subsection{Static test results}

Load- deflection responses and crack patents of static tests are presented in Fig. 3. For the specimen of SPR0.8, the diagonal crack was found obviously, and there are one bending crack near the mid-span can be found with carefully checking as the red line marked on specimen. The DIC results corresponding to the loaddeflection curve were shown in Fig. 3 where the horizontal displacement cloud map was chosen to delicate the failure evolution. The force increased with the increment of deflection near to linear before the point of S1, the cracks haven't emerged. After the point of S1, the force increased non-linearly with the increment of deflection for the bending crack was found at the bottom of mid-span of beam. Until to the point S2, the discontinuity of displacement was observed at the bottom of left part of beam. After the point of S3, the dialogue crack formed and propagated the loading point, and the force didn't increase mostly as the increasing of deflection, then the dialogue crack evaluated to the main crack, and the force was decreased with the develop of deflection slowly after the point of S4.

As the results shown, for the reinforced concrete beam under static loading, the failure mode is bending firstly, and translates to shearing with the increasing of deflection. During the bending stage, the bearing loading will increase with the increment of deflection, but the increment of loading will stop even to decay under shearing stage. For the bending failure, the longitudinal reinforcements play an important role for the increasing of loading after the linear stage in the load- deflection 
curves, but the shearing capacity lost for the structure without stirrups.

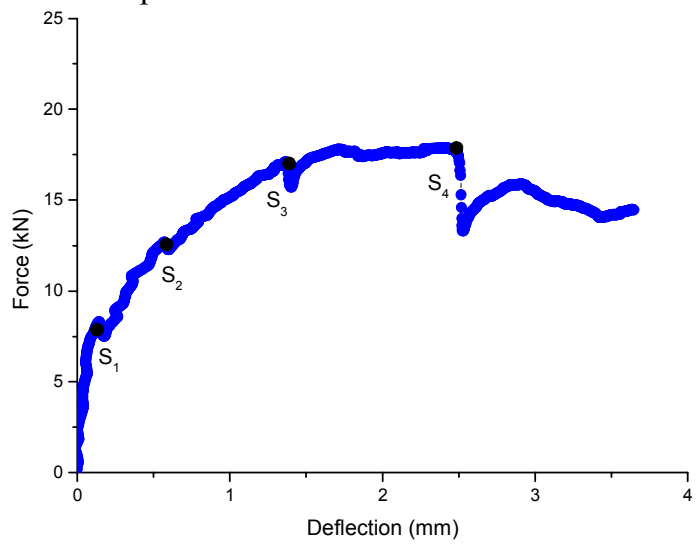

(a)
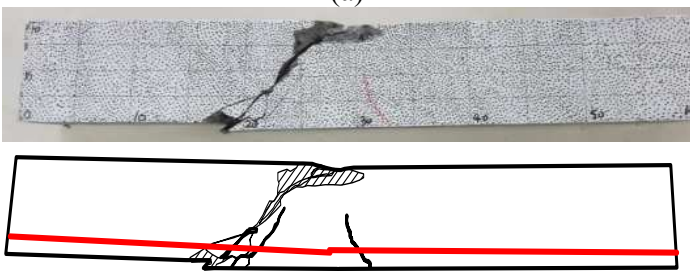

(b)
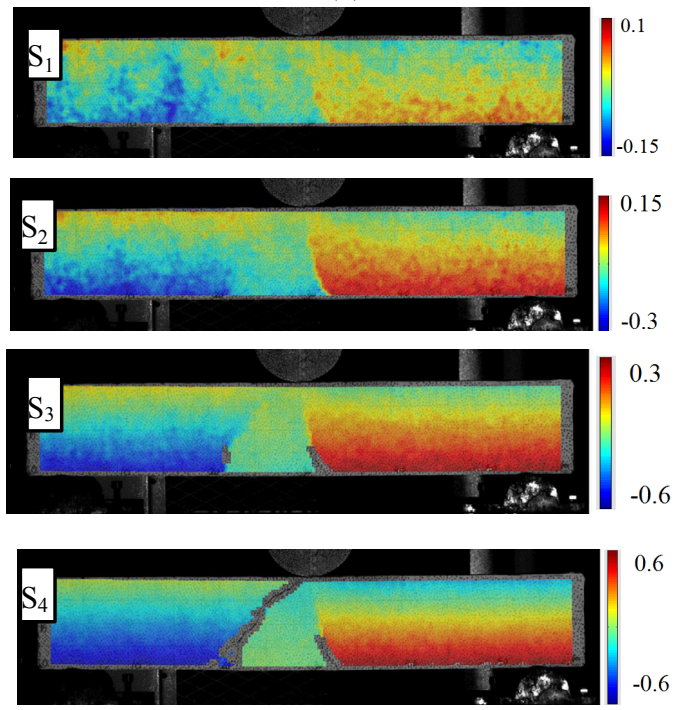

(c)

Fig. 3. Force-deflection curves (a), crack patterns (b) and horizontal displacement $(\mathrm{mm})$ evolution (c) of static tests.

\subsection{Impact test results}

Details of cracks profiles and failure model of beam at each test evens are summarized in Fig. 4: Typical flexure failure was observed for the drop height of $1.2 \mathrm{~m}, 2.4 \mathrm{~m}$, and shear failure was found in the event of PR0.8-3.6 and PR0.8-4.8. For the flexure failure crack patterns, only one bending crack developed from the bottom surface towards top surface of the beam at the impact point. With the increment of the drop height to $3.6 \mathrm{~m}$, a flexural crack was found at the mid-span and a diagonal crack formed in the left half side. For the drop height to $4.8 \mathrm{~m}$, the failure was more severe than $3.6 \mathrm{~m}$ and several dialogue cracks were found. As the result of
PR0.8 series, failure model of RC beam transforms from flexural failure to shear failure with the increment of drop height. Moreover, all the impact evens, the longitudinal reinforcements were broken near the middle span.

The impact force and mid-span deflection time history curves for all tests are shown in Fig. 5. For the impact force time history curves, as Fig. 5(a) shown, the peak impact force increases obviously with the increment of drop height, even the peak force of $4.8 \mathrm{~m}$ three times greater than event of $1.2 \mathrm{~m}$. And the duration of peak is so short less than $0.5 \mathrm{~ms}$ for all impact events. After the peak, the magnitude of impact force is very low corresponding to the balance with reaction force of supporters. All the deflection data is the movement of mid-span of beam determined by DIC method as Fig. 5(b) shown. It is clearly that the deflection developed faster with the increasing of drop height.

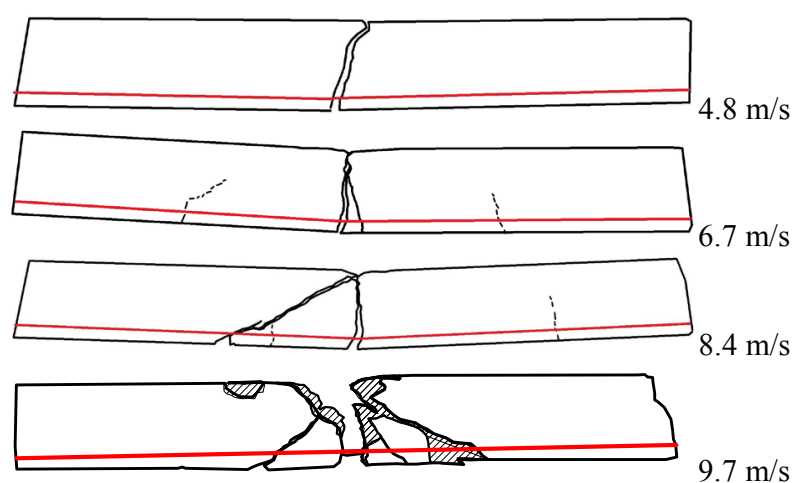

Fig. 4. Crack patterns of impact tests under different initial height of $1.2 \mathrm{~m}$ (a), $2.4 \mathrm{~m}$ (b), $3.6 \mathrm{~m}$ (c), and $4.8 \mathrm{~m}$ (d).

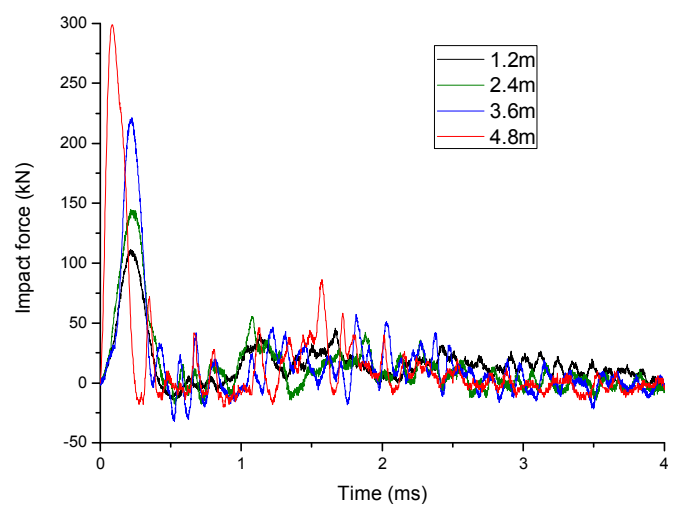

(a)

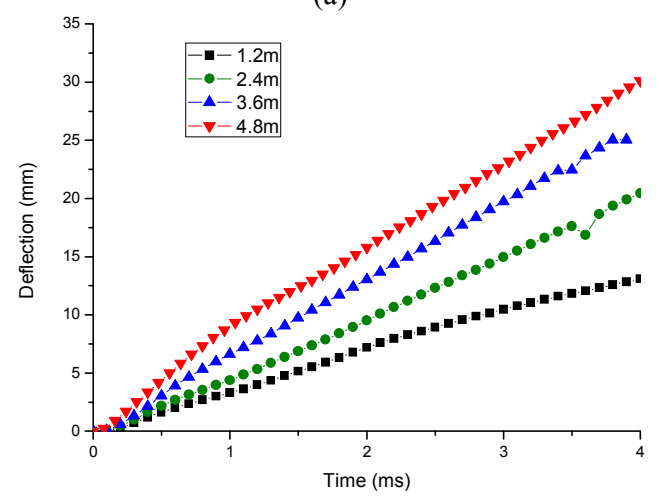

(b)

Fig. 5. Impact force (a) and mid-span deflection (b) of impact tests. 
To investigate the shearing failure of reinforced concrete beam under impact loading, the event of PR0.84.8 was chose in this paper. The DIC results corresponding to the impact force-deflection curve were shown in Fig.6 where the horizontal displacement cloud map was chosen to delicate the failure evolution. At the point of D1, no crack was found, and a single crack could be determined at bottom of middle span of beam when the force reached to the maximum point of D2. After the central bending crack emerged, the impact force decayed sharply. At the point of D3, a dialogue crack was observed at the left part of beam, and the initiation of this crack did not located at the bottom of beam but the upside of beam near the impact point. At the point of D4, near the end of peak of impact force, dialogue cracks can be found at both side of beam. Until to D6 point, all cracks has been mature. As mentioned above, reinforced concrete beams fail in a flexural failure model at slow rates of loading and in shear failure model at high rate impact loading relatively. Though the dialogue crack was obvious for the shear model crack patterns, the central flexural crack and hair line cracks can be found too. That means the failure of beams under high rate impact loading is the mixture of shear model and flexural model.
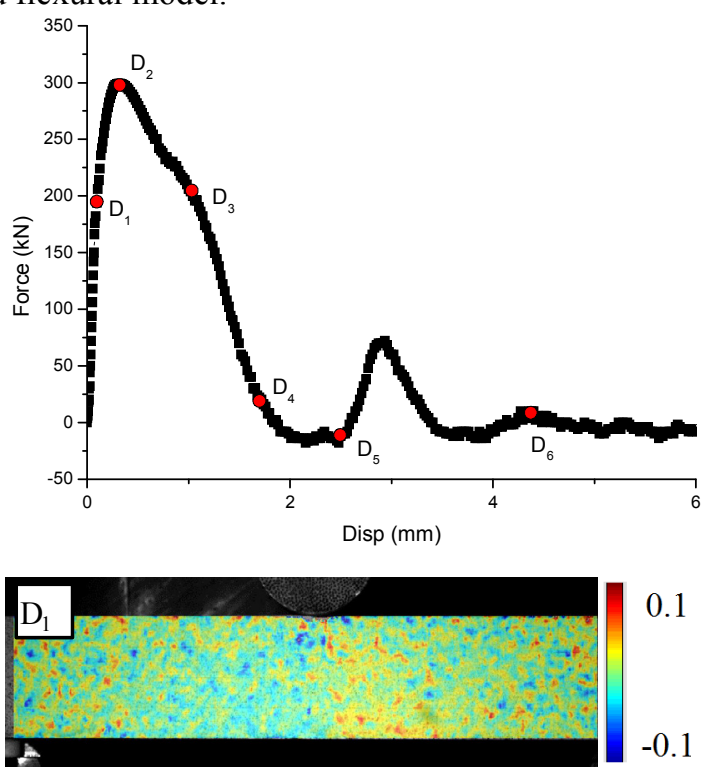

0.1

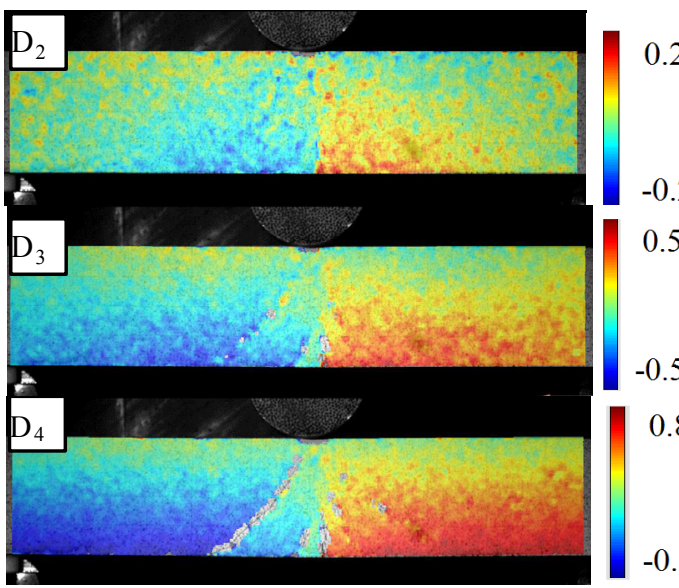

$-0.1$

0.2

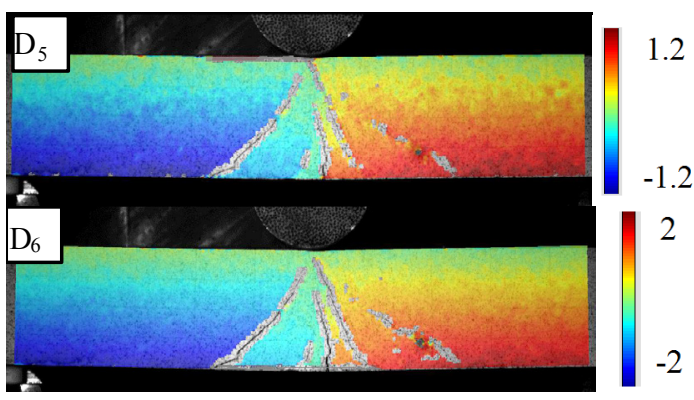

Fig. 6. Force-deflection curves and horizontal displacement (mm) evolution of PR0.8 - $4.8 \mathrm{~m}$.

DIC can be used to measure the range of strain by calculating a series of pictures record by high speed camera. This method provides a way to investigate the emergency sequence of cracks and access the strain state of failure. The strain distribution along the horizontal line on the central layer of PR0.8- $4.8 \mathrm{~m}$ was plotted in Fig. 7. The obvious increment of strain was found at the time of D3, shear strain and tension strain increased at the same time. That means the shear failure and bending failure have developed during the peak stage of Forcedeflection curves. That is different with the emergence sequence of cracks under static tests. So the mechanical parameters of peak stage should be considered for the resistance of concrete beam under impact loading.

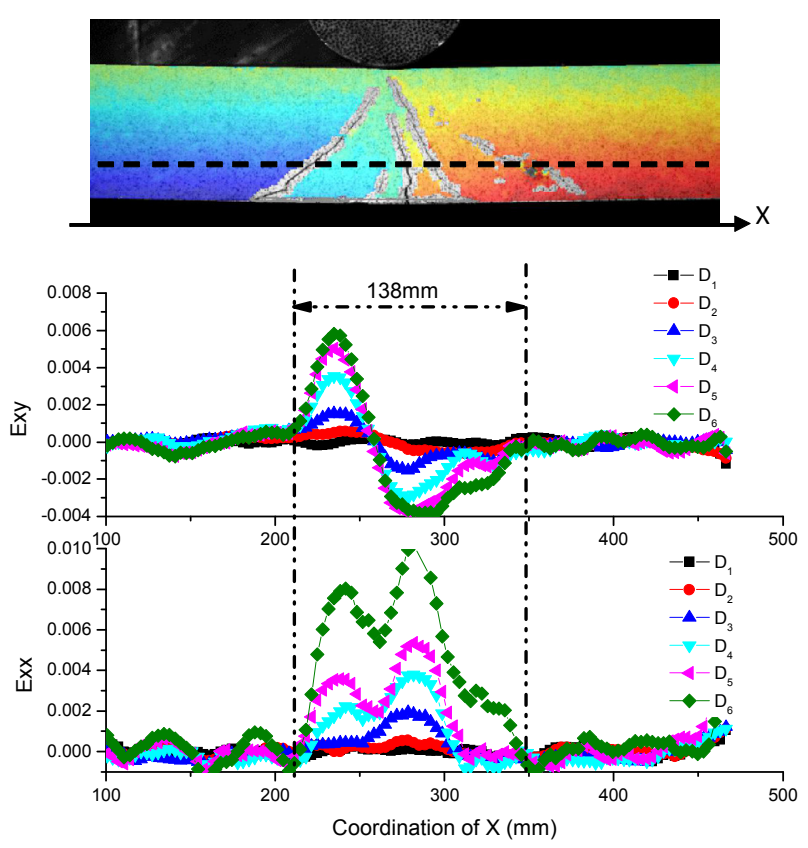

Fig. 7. Strain distribution along the horizontal line on the central layer of PR0.8 - $4.8 \mathrm{~m}$.

\section{Summary}

This paper presents an experimental program of reinforced concrete beam without stirrups tested by impact three-point-bending under different initial velocity (drop height). As the results shown, for the static events, the failure mode is bending firstly, and then translates to shearing. The longitudinal reinforcements play an important role for the increasing of loading 
during bending stage. For the impact events, reinforced concrete beams failed in a flexural failure model at slow rates of loading and in shear failure model at high impact loading rate relatively. Moreover, the shear failure and bending failure have developed during the peak stage of Force-deflection curves. That is different with the emergence sequence of cracks under static tests. So the mechanical parameters of peak stage should be considered for the resistance of concrete beam under impact loading.

\section{References}

1. N. Banthia, S. Mindess and A. Bentur, Impact behavior of concrete beams, Materials and Structures, 20, 293-302 (1987)

2. N. Banthia, S. Mindess and A. Bentur, Impact testing of concrete using a drop-weight impact machine, Experimental Mechanics, 29(1), 63-69 (1989)
3. N. Kishi , O. Nakano, K.G. Matsuoka and T. Anto, Impact behavior of shear-failure-type RC beams without shear rebar. International Journal of Impact Engineering, 27(9), 955-968 (2002)

4. K. Fujikake, B. Li B, and S. Soeun, Impact response of reinforced concrete beam and its analytical evaluation. Journal of Structural Engineering, 135(8), 938-950 (2009)

5. S. Saatici, F. Vecchio, Effects of shear mechanisms on impact behavior of reinforced concrete beams, ACI Structure Journal, 106(1), 78-86 (2009)

6. S. Saatici, F. J. Vecchio, Non-linear finite element modeling of reinforced concrete beams under impact, ACI Structure Journal, 106(5), 717-725 (2009) 
